\title{
Chorioamnionitis, not epidural analgesia, is associ- ated with maternal fever during labour
}

\author{
[La chorio-amnionite est associée à la fièvre puerpérale pendant le travail, mais \\ non l’analgésie épidurale]
}

\author{
Manuel C. Vallejo MD, * Bupesh Kaul MD, ${ }^{*}$ Lauri J. Adler MD, * Amy L. Phelps PhD, $\mathfrak{S}$ \\ Catherine M. Craven MD, $†$ Trevor A. Macpherson MD, $†$ Richard L. Sweet MD, $\ddagger$ Sivam Ramanathan MD*
}

Purpose: Maternal fever is associated with chorioamnionitis and has been linked to labour epidural analgesia (LEA). The purpose of this study was to determine possible associations between LEA and chorioamnionitis, maternal fever, operative delivery rate, and neonatal outcome.

Methods: Data from 14,073 patients were entered into a database over a two-year period. From this database, 62 nulliparous parturients with clinical chorioamnionitis (amnionitis), but without LEA were identified (Group I). Two other groups who received LEA were matched for parity and gestation: Group II - LEA with concomitant amnionitis $(n=50)$ and, Group III - LEA without concomitant amnionitis $(n=20 \mathrm{I})$. The diagnosis of chorioamnionitis was confirmed by histologic examination. Results are expressed as mean $\pm \mathrm{SD}$ and analyzed at $P<0.05$ using ANOVA or Chi-square. Results: No differences were noted among the groups in the operative delivery rate or Apgar scores at five minutes. The percentage of patients with maternal fever during labour $\left(38.0^{\circ} \mathrm{C}\right)$ with amnionitis was significantly less in Group III compared to the other groups (100\% in both Groups I and II vs 1.0\% in Group III; $P=0.000$ ). Likewise, Group III had a lower percentage of neonates with Apgar scores $<7$ at one minute $35.5 \%$ in Group I, 20.0\% in Group II, 17.4\% in Group III; P=0.010). The percentage of histologic chorioamnionitis was significantly higher in both amnionitis groups compared to Group III (67.7\% in Group I, 56.0\% in Group II, 4.0\% in Group III; $P=0.000)$.

Conclusion: LEA without chorioamnionitis is not associated with maternal fever $\left(38.0^{\circ} \mathrm{C}\right)$, increased operative delivery rates or low Apgar scores.
Objectif : La fièvre puerpérale est associée à la chorio-amnionite et a été reliée à l'analgésie épidurale pendant le travail (AET). L'objectif de la présente étude était de déterminer les associations possibles entre AET et, chorio-amnionite, fièvre puerpérale, taux de césarienne et évolution néonatale.

Méthode : Pendant deux ans, on a inscrit dans une base de données les informations concernant 14073 patientes. À partir de cette base de données, on a repéré 62 parturientes nullipares qui présentaient une chorio-amnionite clinique, sans AET (groupe I). Deux autres groupes de femmes qui ont reçu une AET ont été appariés pour la parité et la gestation : le groupe II qui comportait une AET et une amnionite concomitante $(n=50)$, et le groupe III avec AET mais sans amnionite concomitante $(n=201)$. Le diagnostic de chorio-amnionite a été confirmé par un examen histologique. Les résultats ont été exprimés par la moyenne \pm l'écart type et analysés à $P<0,05$ en utilisant une analyse de variance ou la méthode du Chi2.

Résultats : Aucune différence intergroupe n'est apparue quant au taux de césarienne ou à l'indice d'Apgar à cinq minutes. Le pourcentage de patientes atteintes de fièvre puerpérale pendant le travail $\left(38,0^{\circ} \mathrm{C}\right)$ et d'amnionite a été significativement moindre dans le groupe III comparé aux deux autres groupes ( $100 \%$ dans les groupes I et II vs I,0 \% dans le groupe III ; $P=0,000)$. Aussi, le groupe III a présenté un pourcentage plus faible de nouveau-nés avec un indice d'Apgar < 7 à une minute (35,5\% dans le groupe I, 20,0\% dans le groupe II, $17,4 \%$ dans le groupe III ; $P=0,010$ ). Le pourcentage de chorioamnionite histologique $a$ été significativement plus élevé dans les deux groupes avec amnionite comparés au groupe III (67,7\% dans le groupe I, 56,0 \% dans le groupe II, 4,0\% dans le groupe III ; $P=0,000$ ).

Conclusion : L'AET sans chorio-amnionite n'est pas associée à la fièvre puerpérale $\left(38,0^{\circ} \mathrm{C}\right)$, à un taux élevé de césarienne ou à un faible indice d'Apgar.

From the Departments of Anesthesiology, ${ }^{*}$ Pathology, $†$ Obstetrics and Gynecology, $\ddagger$ Magee-Womens Hospital, University of Pittsburgh School of Medicine, and Quantitative Sciences (School of Business), $\$$ Duquense University, Pittsburgh, Pennsylvania, USA. Address correspondence to: Dr. Manuel C. Vallejo, Department of Anesthesiology, Magee-Womens Hospital, University of Pittsburgh

School of Medicine, Pittsburgh, PA, USA. Phone: 412-641-4260; Fax: 412-641-4766; E-mail: vallejomc@anes.upmc.edu Accepted for publication July 18, 2001. Revision accepted August 29, 2001. 
EVERAL studies have documented an association between labour epidural analgesia (LEA) and increased maternal temperature. ${ }^{1-3}$ Lieberman et al. ${ }^{1}$ concluded in a retrospective study that LEA is strongly associated with the occurrence of maternal intrapartum fever and an increased neonatal sepsis evaluation rate (NSER), but the issue of chorioamnionitis was not considered in their study. Dashe et al. ${ }^{4}$ found epidural analgesia is associated with intrapartum fever, but only in the presence of histologic chorioamnionitis. The purpose of this study is to explore the relationship between LEA, chorioamnionitis, maternal fever $\left(38.0^{\circ} \mathrm{C}\right)$, operative delivery rate, and neonatal outcome.

\section{Methods}

Magee-Womens Hospital (MWH) is a tertiary care maternity facility with more than 7,500 deliveries annually and an $80 \%$ labour epidural placement rate. $\mathrm{MWH}$ maintains an obstetrical database for the purpose of continuous quality improvement (CQI) pertaining to maternal and neonatal outcome. A dedicated database coder collects information on all patients admitted to the MWH labour and delivery suite and enters this data into a computerized database (SPSS Inc., Chicago, IL, USA). The patient's medical record number (MR\#) is set as the key field for the database. Data retrieval was compiled over a two-year period for all patients who where admitted to the MWH labour and delivery suite from January 1, 1998 to December 31, 1999. The diagnosis of clinical chorioamnionitis (amnionitis) was confirmed by matching the MR\# in the database and by individual review of the patient's medical chart. The diagnosis of acute histologic chorioamnionitis was confirmed by matching the MR\# with the placental pathology report. Approval for this database study was obtained from the MWH Institutional Review Board.

Epidural blocks are inserted at the request of the patient and with approval of the obstetrician. LEA blocks are performed in the sitting position at the L3-L4 to L4-L5 intervertebral space using the loss of resistance to air technique. Bupivacaine $0.25 \%$ or ropivacaine $0.2 \%$ is used for induction of analgesia to a T10 dermatomal level followed by a continuous infusion of $0.125 \%$ bupivacaine or $0.125 \%$ ropivacaine with fentanyl $\left(2 \mu \mathrm{g} \cdot \mathrm{mL}^{-1}\right)$ at $10-12 \mathrm{~mL} \cdot \mathrm{hr}^{-1}$.

Diagnostic criteria used at our institution for the diagnosis of clinical chorioamnionitis (amnionitis) includes fever $\left(38.0^{\circ} \mathrm{C}\right)$ plus one or more of the following: maternal tachycardia, fetal tachycardia, uterine tenderness, foul smelling amniotic fluid, or maternal leukocytosis. All patients admitted to the labour suite received an initial vaginal examination to determine cervical dilatation, station, effacement and were subsequently checked at the discretion of the attending obstetrician. Laboratory examination was ordered by the obstetrician as determined by medical history, obstetrical history and current clinical situation. Maternal temperature was measured every four hours or every hour if febrile. Maternal vital signs (heart rate, blood pressure, respiratory rate) were measured every hour as per institutional labour and delivery pathway protocol. External fetal heart rate was monitored continuously or by internal fetal scalp electrode if external fetal heart tones could not be monitored continuously.

From the CQI database, 62 nulliparous parturients who did not receive LEA, but had amnionitis at $34.0 \pm$ 7.0 weeks gestation (Group I) were identified. In order to match other nulliparous parturients who did receive LEA, the $95 \%$ confidence interval was used to estimate the true mean gestation at $34 \pm 2.0$ weeks. The matched patients were then divided into two groups: LEA with concomitant amnionitis (Group II) and LEA without concomitant amnionitis (Group III).

Maternal data retrieved from the CQI database included: parity, gestation, age, weight, group B- $B$ hemolytic streptococcal colonization status (GBBS), preterm ( $<37$ weeks gestation), premature rupture of membranes (PROM), oxytocin augmentation, maternal fever during labour $\left(38.0^{\circ} \mathrm{C}\right)$, and mode of delivery (Cesarean section, vaginal delivery, and vacuum/forceps). Maternal temperature was measured orally using a sublingual thermometer (IVAC Corporation, San Diego, CA, USA).

Neonatal outcome data retrieved from the CQI database included; Apgar scores $<7$ at one minute, and $<9$ at five minutes, birth weight, and NSER. Indications for neonatal sepsis evaluation at our institution include; maternal fever during labour (38.0C), maternal diagnosis of clinical chorioamnionitis (amnionitis), prolonged rupture of membranes $>24 \mathrm{hr}$, birth weight $<2,500$ grams, preterm gestational age $<37$ weeks gestation, meconium and/or respiratory distress at birth, hypothermia at birth, GBBS colonization, and maternal pre-ecclampsia and/or hypertension.

Statistics describing interval data are expressed as mean \pm SD. Statistical comparison between the three groups was analyzed using one-way analysis of variance (ANOVA). Statistics describing nominal data are reported in percentages. Statistical comparison between the three groups' proportions was analyzed using the Chi-square method. ${ }^{5}$ The $P$-value for each univariate test are reported. A $P$-value less than 0.05 was considered statistically significant. 
Results

Data from all 14,073 patients admitted to MWH labour and delivery suite were evaluated retrospectively over a two-year period. From the CQI database, 6,205 parturients $(44.1 \%)$ were nulliparous of which 62 parturients who did not receive LEA had clinical chorioamnionitis (amnionitis) at 34.0 weeks gestation (Group I, Table I). Group II consisted of 50 parturients with LEA, and with concomitant amnionitis. Group III consisted of 201 parturients with LEA, but without concomitant amnionitis (Table I).

The overall incidence of clinical chorioamnionitis (amnionitis) at our institution during the two-year period was $6.7 \%(944 / 14,073)$ and the incidence of amnionitis in nulliparous parturients was $9.4 \%$ $(582 / 6,205)$.

Demographic data are presented in Table I. No differences were noted with respect to gestational age and maternal age and weight. No differences were noted in the GBBS colonization rate or in the percentage of patients with PROM (Table I). More patients in both LEA Groups II and III presented preterm (<37 weeks gestation) compared to Group I (Table I).

Table II presents maternal labour and delivery outcome data. No differences were noted in the operative delivery rate. The percentage of patients with maternal fever plus one or more criterion used for the diagnosis of amnionitis was significantly less in Group III

TABLE I Demographic data, nulliparity, gestation and Group B- $B$ hemolytic streptococcus status

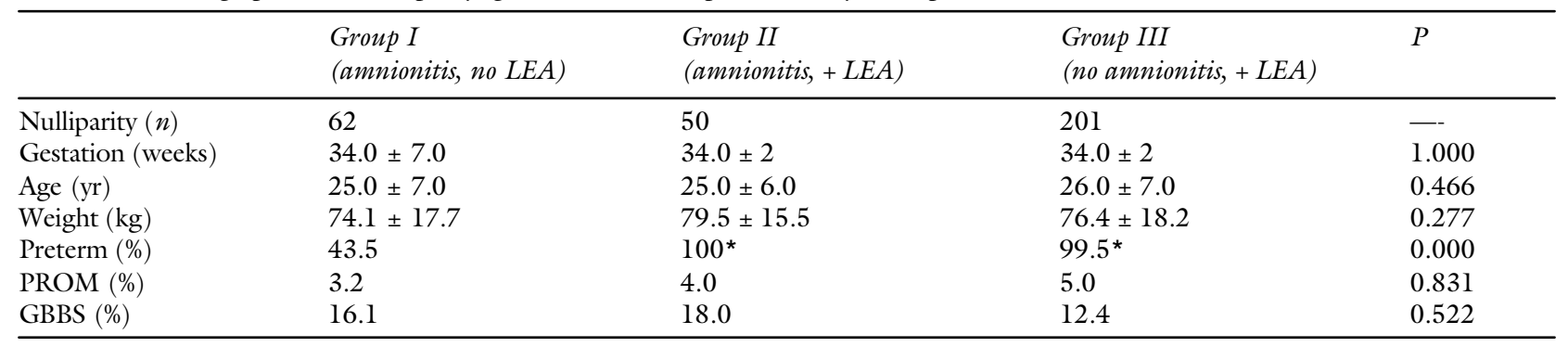

Group I=amnionitis without concomitant labour epidural analgesia (LEA); Group II=LEA with concomitant amnionitis; Group III=LEA without concomitant amnionitis; Preterm $=<37$ weeks gestation; PROM=premature rupture of membranes; GBBS=group B- $\beta$ hemolytic streptococcus positive. ${ }^{*} P<0.05$ compared to Group I.

TABLE II Maternal outcome, oxytocin augmentation, and maternal fever during labour

\begin{tabular}{lllll}
\hline & $\begin{array}{l}\text { Group I } \\
\text { (amnionitis, no LEA) }\end{array}$ & $\begin{array}{l}\text { Group II } \\
\text { (amnionitis, +LEA) }\end{array}$ & $\begin{array}{l}\text { Group III } \\
\text { (no amnionitis, + LEA) }\end{array}$ & $P$ \\
\hline Delivery mode (\%) & & & & 16.4 \\
Cesarean section & 14.5 & 16.0 & 83.6 & 0.938 \\
Vaginal delivery & 85.5 & 84.0 & 15.9 & 0.938 \\
Vacuum/forceps & 8.1 & 14.0 & $39.3^{*}$ & 0.298 \\
Oxytocin (\%) & 9.7 & 24.0 & $1.0 * \#$ & 0.000 \\
Fever during labour (\%) & 100.0 & 100.0 & 0.000 \\
\hline
\end{tabular}

${ }^{*} P<0.05$ compared to Group I; \#P<0.05 compared to Group II, fever during labour=fever plus one or more criteria used for the diagnosis of amnionitis (see text). For other abbreviations see Table I.

TABLE III Neonatal outcome

\begin{tabular}{llll}
\hline & $\begin{array}{l}\text { Group I } \\
\text { (amnionitis, no LEA) }\end{array}$ & $\begin{array}{l}\text { Group II } \\
\text { (amnionitis, +LEA) }\end{array}$ & $\begin{array}{c}\text { Group III } \\
\text { (no amnionitis, + LEA) }\end{array}$ \\
\hline One-minute Apgar <7 (\%) & 35.5 & 20.0 & $17.4^{*}$ \\
Five-minute Apgar <9 (\%) & 33.9 & 30.0 & 27.4 \\
Birth weight (kg) & $2.57 \pm 1.19$ & $2.46 \pm 0.70$ & $2.24 \pm 0.51^{*} \#$ \\
LBW (<2.5 kg) (\%) & 32.3 & 52.0 & $72.6^{*} \#$ \\
Overall NSER (\%) & 32.3 & 52.0 & $55.0^{*}$ \\
LBW neonates with NSER (\%) & 100.0 & 100.0 & 0.607 \\
\hline
\end{tabular}

LBW=low birth weight; NSER=neonatal sepsis evaluation rate; * $P<0.05$ compared to Group I; \#P $<0.05$ compared to Group II; for other abbreviations see Table I. 


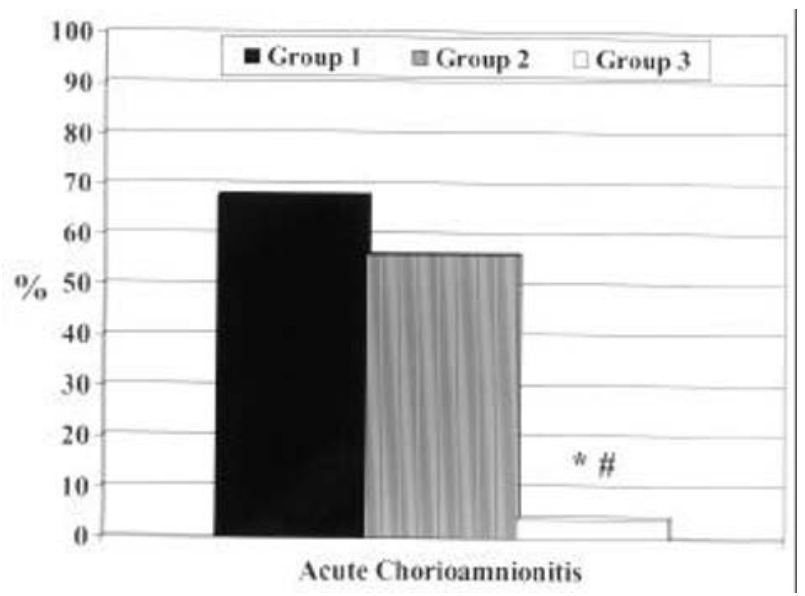

FIGURE Percentage of parturients with histologic acute chorioamnionitis. ${ }^{*} P<0.05$ compared to Group I, $\# P<0.05$ compared to Group II, for other abbreviations see Table I.

(Table II). Group III was more likely to receive oxytocin augmentation compared to Group I (Table II).

Neonatal outcome data are presented in Table III. The percentage of neonates with one minute Apgar scores $<7$ was significantly less in Group III compared to Group I. No differences were noted in the percentage of neonates with Apgar scores $<9$ at five minutes. Group I had the highest mean birth weight and the lowest percentage of low birth weight (LBW) $<2.5 \mathrm{~kg}$ neonates. The overall NSER was highest in Group III compared to Groups I and II (Table III). However, $100 \%$ of the neonates in Groups I and II weighing less than $2.5 \mathrm{~kg}$ had a neonatal sepsis evaluation compared to only $76 \%$ of the neonates in Group III (Table III).

The figure shows the percentage of parturients with histologic acute chorioamnionitis in all groups. Group III had the lowest percentage of parturients with histologic acute chorioamnionitis compared to the other two groups.

\section{Discussion}

The association between LEA and maternal fever is a subject of much debate as evidenced by the attention this subject has been given in the literature, the lay press and media. ${ }^{1-3,6,7}$ Our results show LEA without concomitant amnionitis is not associated with elevated maternal fever, increased operative delivery rate or lower Apgar scores. Lieberman et al. ${ }^{1}$ in a retrospective study of 1,934 nulliparous women found the use of epidural analgesia to be strongly associated with maternal intrapartum fever and an increased NSER, but it is not clear how many of the patients in their study had chorioamnionitis. If Lieberman et al. ${ }^{1}$ had considered the issue of chorioamnionits, their conclusions on epidural analgesia may have been different.

The incidence of aminionitis in our institution is comparable to that in other tertiary care centers. ${ }^{8}$ Looff and Hager describe amnionitis as a significant cause of maternal fever in obstetrics. ${ }^{9}$ Our data concurs with this fact in that all patients in Groups I and II with amnionitis also had fever during labour compared to only $1 \%$ in Group III.

Epidural analgesia can elevate maternal temperature, but not enough to cause maternal fever $\left(38.0^{\circ} \mathrm{C}\right) .3,10$ This is evidenced by the low incidence of maternal fever in Group III (LEA without concomitant amnionits). The highest rates of maternal fever occurred in both amnionitis groups. Morishima has shown that a greater than $2^{\circ} \mathrm{C}$ increase in maternal temperature above baseline is associated with decreased uterine blood flow and significant fetal compromise. ${ }^{11}$ However, small increases in maternal temperature $\left(0.5-1.5^{\circ} \mathrm{C}\right)$ that normally occur with LEA, are advantageous to fetal well being in that uterine blood flow is increased, uterine vascular resistance is decreased, fetal blood oxygen tension is increased, with no changes in fetal carbon dioxide tension or $\mathrm{pH} .{ }^{10}$

Our data confirm the results of Dashe et al. ${ }^{4}$ who found epidural analgesia to be associated with maternal fever, but only in the presence of histologic chorioamnionitis. However, our study is different from Dashe's in that we also looked at both maternal and neonatal outcome. Both amnionitis groups had a significantly higher incidence of histologic chorioamnionitis compared to Group III (Figure). Even though amnionitis was not suspected in Group III, the main reason for placental histologic examination was the high incidence of preterm labour.

Negishi et al. ${ }^{2}{ }^{2}$ believe inflammation and/or infection causes hyperthermia, and not epidural analgesia itself, which is consistent with our study and Dashe's results. Negishi found that small concentrations of iv narcotics inhibit the febrile response, while epidural analgesia with or without narcotic does not attenuate this response. ${ }^{12}$ Hyperthermia during epidural analgesia should not be considered a result of the epidural alone, and potential sources of inflammation/infection (chorioamnionitis) should be aggressively pursued and treated.

Groups II and III had a higher percentage of parturients who presented in preterm labour compared to Group I (Table I), and hence a lower mean birth weight and a higher percentage of babies with LBW 
(Table III). Raghavan et al. identified both preterm delivery and LBW as major factors associated with neonatal sepsis. ${ }^{13}$ Groups II and III had a higher NSER due to the higher percentage of prematurity and LBW compared to Group I.

Patients with GBBS colonization are given iv penicillin during labour. Antibiotic coverage explains why the GBBS colonization rate does not make a difference in the febrile response to epidural analgesia and chorioamnionitis in our institution. More parturients in Group III received oxytocin augmentation than Group I. This is explained by the fact that oxytocin augmentation is often used in conjunction with epidural analgesia at our institution.

In conclusion, LEA without concomitant chorioamnionitis is not associated with elevated maternal fever, increased operative delivery rate or lower Apgar scores. On the other hand, chorioamnionitis with, or without concomitant LEA is associated with a higher percentage of maternal fever during labour. Any study comparing the effect of LEA on maternal thermoregulation should consider the issue of chorioamnionitis.

Acknowledgements

The authors want to thank David Crowe and Elizabeth DeAngelo for their help with data collection and analysis from the Magee-Womens Hospital Obstetrical database.

\section{References}

I Lieberman E, Lang JM, Frigoletto F Jr, Richardson DK, Ringer $S A$, Cohen $A$. Epidural analgesia, intrapartum fever, and neonatal sepsis evaluation. Pediatrics 1997; 99: 415-9.

2 Philip J, Alexander JM, Sharma SK, Leveno KJ, McIntire DD, Wiley J. Epidural analgesia during labor and maternal fever. Anesthesiology 1999; 90: 1271-5.

3 Vinson DC, Thomas R, Kiser T. Association between epidural analgesia during labor and fever. J Fam Pract 1993; 36: 617-22.

4 Dashe JS, Rogers BB, McIntire DD, Leveno KJ. Epidural analgesia and intrapartum fever: placental findings.

Obstet Gynecol 1999; 93: 341-4.

5 Glantz SA. Primer of Biostatistics, $4^{\text {th }}$ ed. New York: McGraw Hill, 1997.

6 Gilbert S. Labor pain relief tied to problems for infants. The New York Times. New York, NY: The New York Times Company, 1997.

7 Viscomi CM, Manullang T. Maternal fever, neonatal sepsis evaluation, and epidural labor analgesia. Reg Anesth Pain Med 2000; 25: 549-53.

8 Alexander JM, McIntire DM, Leveno KJ.
Chorioamnionitis and the prognosis for term infants. Obstet Gynecol 1999; 94: 274-8.

9 Looff JD, Hager WD. Management of chorioamnionitis. Surg Gynecol Obstet 1984; 158: 161-6.

10 Camann WR. Epidural analgesia in labor and fetal hyperthermia (Letter). Obstet Gynecol 1993; 81: 316-7.

11 Morishima HO, Glaser B, Niemann WH, James LS. Increased uterine activity and fetal deterioration during maternal hyperthermia. Am J Obstet Gynecol 1975; 121: 531-8.

12 Negishi C, Lenhardt R, Ozaki M, et al. Opiods inhibit febrile responses in humans, whereas epidural analgesia does not. An explanation for hyperthermia during epidural analgesia. Anesthesiology 2001; 94: 218-22.

13 Raghavan M, Mondal GP, Bhat VV, Srinivasan S. Perinatal risk factors in neonatal infections. Indian J Pediatr 1992; 59: 335-40. 